\title{
Synthesis, spectroscopic characterization and powder XRD study of 4-(5-(ethylthio)-1,3,4-oxadiazole-2-yl) aniline
}

\author{
Emad Ghanem ${ }^{1, ~ *, ~ S a h a r ~ A l-H a r i r i ~}{ }^{1}$, Abeer Ghanem ${ }^{2}$, Lama Aouda ${ }^{2}$ \\ ${ }^{1}$ Department of Chemistry, Faculty of Sciences, Damascus University, Damascus, Syrian Arab Republic \\ ${ }^{2}$ Higher Institute of Laser Research, Damascus University, Damascus, Syrian Arab Republic
}

Email address:

ganememad@yahoo.com (E. Ghanem)

\section{To cite this article:}

Emad Ghanem, Sahar Al-Hariri, Abeer Ghanem, Lama Aouda. Synthesis, Spectroscopic Characterization and Powder XRD Study of 4-(5-(Ethylthio)-1,3,4-Oxadiazole-2-yl) Aniline. American Journal of Applied Chemistry. Special Issue: Development of Liquid Crystalline Stationary Phases for Liquid and Gas Chromatographic Separations. Vol. 3, No. 5-1, 2015, pp. 1-6.

doi: 10.11648/j.ajac.s.2015030501.11

\begin{abstract}
In order to investigate the separation mechanism of liquid crystals stationary phases based on an oxadiazole moiety, new 1,3,4-oxadiazole derivative as side mesogenic arm in liquid crystals was prepared, and its structural spectroscopic data were studied in this paper. A powerful indication about the relationship between molecular structure and alignment properties is described. Such information is indispensable for the design and synthesis new liquid crystals stationary phases of high separation efficiency.
\end{abstract}

Keywords: Oxadiazole, Liquid Crystal, Characterization, XRD, Synthesis

\section{Introduction}

The design of novel liquid crystals as stationary phases in Gas chromatography involves selection of a suitable core fragment, linking group, and terminal functionality. However, these considerations play an important role in this interesting state of soft matter [1].

Over many years, a large number of liquid crystalline compounds containing heterocyclic units has been synthesized [2]. This research field has grown even more in recent years because of improvements in synthetic methodologies.

Heterocyclics are of great importance as core units in liquid crystals (LCs), because the incorporation of heteroatoms can result considerable changes in the corresponding liquid crystalline phases and/or in the physical properties of the observed phases.

The heterocyclic compounds are used, they are easily prepared, and present a large dipolar moment.

It is well known in literatures, nitrogen and oxygen containing compounds are essentially used in medicine for the treatment of different kinds of fungal and bacterial infections along with the treatment of cancer [3]. The organic moiety having nitrogen atom results towards high efficiency against various diseases [4].
There has been also much interest in the synthesis and characterization of compounds containing 1,3,4-oxadiazole unit owing to their interesting unique properties, such as liquid crystalline and nonlinear optical properties, as well as their applications in other fields [5-10].

Among these materials, Schiff base LCs, which particularly gathered attention, especially with respect to their properties as stationary phases in gas chromatography (SPGC) for the separation of isomers. In addition, it has been demonstrated that 1,3,4-oxadiazole unit is a suitable structural element to be incorporated in thermotropic LCs.

Many LCs containing oxadiazole ring were developed, and most researches focused on the characterization of LCs by traditional methods, in spite using new techniques; such polarized optical microscope (POM), or even inverse GC.

However, just few studies were applied X-Ray diffraction to get closer view of the molecular LC.

If we examine the main representative unit of the LCs, we will gain more details about the separation mechanism inside the stationary phase of gas chromatographic column.

The crystal structures of a series of oxadiazole derivatives were examined, in order to obtain structural information relevant to their possible modes of association with the Schiff 
base LCs, as well as of other substances in biological systems [11].

Therefore, the question to obtain new molecular design arises as; What is the secret behavior of isomers separation on the stationary phase of GC, and How to modify the substitution pattern of the 1,3,4-oxadiazole moiety in such a way that resulted liquid crystalline compounds, will probably exhibiting highly efficiency?

The goal of this study is the synthesis and full structural study of one of 1,3,4-oxadiazole derivatives, which was used in our earlier studies as a main linking unit of many liquid crystal stationary phases [9]. These LCs stationary phases showed high affinity in GC for the separation of close boiling isomers, such as xylene, cresol, decaline, phenols, and aromatic isomers.

\section{Experimental}

\subsection{Materials and Methods}

The chemical structure of compound III is confirmed by traditional spectroscopic methods; Infrared spectrum was measured on a Jasco-300E-FTIR spectrophotometer. 1H and 13C NMR spectra (400 MHz), were recorded on a MERCURY 400 spectrometer using DMSO- $d_{6}$ as the solvent, $\delta$ values in parts per million (ppm) are relative to external standard TMS (tetramethylsilane). Mass spectrum was recorded by a Finnegan 3300 GC-MS instrument with methane chemical ionization. Elemental analysis was performed in EuroVector EA3000 Elemental analyser. X-ray powder diffraction measurements were performed at room temperature with a APD 2000 Diffractometer using monochromic $\mathrm{Cu} \mathrm{K} \alpha_{1}$ radiation.

The desired compound III is prepared in a three-step procedure initiated from 4-aminobenzoic hydrazide, following the procedure in Scheme 1 [9].

\subsection{Preparation of 5-(4-Aminophenyl)-1,3,4-Oxadiazole-2-Thiol, II}

In brief, 4-aminobenzoic hydrazide (I) ( $3.0 \mathrm{~g}, 0.02$ moles) is dissolved in an absolute EtOH $(20 \mathrm{~mL})$, and cooled to $0^{\circ} \mathrm{C}$. A solution of potassium hydroxide $(1.5 \mathrm{~g}, 0.027$ moles $)$ in absolute EtOH $(10 \mathrm{~mL})$ was added, the mixture stirred for 15 $\mathrm{min}$, then $\mathrm{CS}_{2}(1.21 \mathrm{~mL}, 0.02$ moles) was added dropwise. The reaction was stirred for a further seven hours under reflux, and solvent was removed by rotary evaporator. The resulting solid was dissolved in cold water $(25 \mathrm{~mL})$, and acidified with $10 \%$ $\mathrm{HCl}$ until participation of light yellow crystals (II) with (1.8 g, $60 \%)$ yield.

${ }^{1} \mathrm{H}-\mathrm{NMR}$ (DMSO- $\left.d_{6}\right): 6.00\left(2 \mathrm{H}, \mathrm{bs}, \mathrm{NH}_{2}\right), 6.63-7.52(4 \mathrm{H}$, $\left.\mathrm{dd}, J_{2,3}=8, J_{2,3}=8, \mathrm{CH} ; \mathrm{Ar}\right)$.

${ }^{13} \mathrm{C}$ NMR (DMSO- $\left.d_{6}\right): 108.4(1 \mathrm{C} ; \mathrm{C}-4), 113.5$ (2C; C-2), 127.6 (2C; C-3), 152.6 (1C; C-1), 161.57 (1C; C-5), 176.54 (1C; C-6).<smiles>NNC(=O)c1ccc(N)cc1</smiles>

(I)

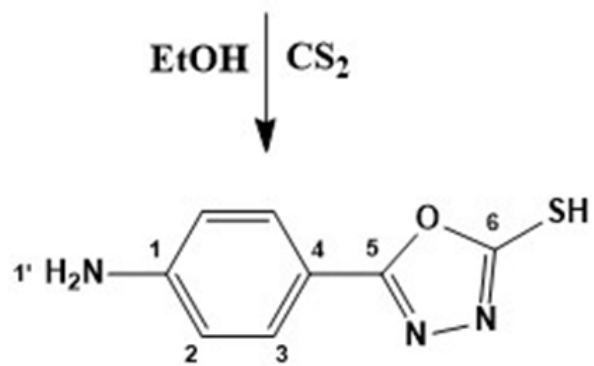

(II)

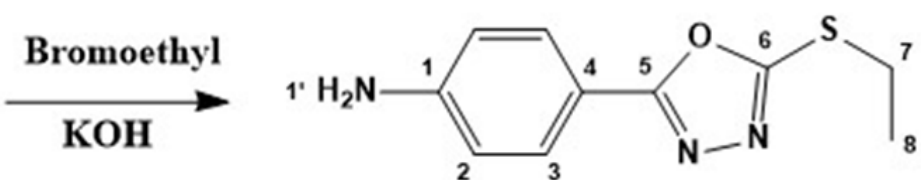

(III)

Scheme 1. Preparation of compound III

\subsection{Preparation of 4-(5-(Ethylthio)-1,3,4-Oxadiazole-2-yl) Aniline, III}

5-(4-amino phenyl)-1,3,4-oxadiazole-2-thiol (II) (3.0 g, 0.016 moles $)$, and potassium hydroxide $(2.74 \mathrm{~g}, 0.042$ moles $)$ dissolved in absolute EtOH $(30 \mathrm{~mL})$, were refluxed for half an hour. After being cooled to room temperature, bromoethyl (1.2 mL, 0.016 moles) was added carefully via a syringe. The reaction was stirred for further three hours under reflux. The solvent was removed in vacuo and the residue poured into cold water to obtain a white solid (III) $(2.26 \mathrm{~g}, 75.3 \%)$.

${ }^{1} \mathrm{H}-\mathrm{NMR}$ (DMSO- $d_{6}$ ): 1.36-1.39 (3 H, t, $\left.J_{1,2}=7.2, \mathrm{H}-8\right)$, 3.21-3.27 (2 H, q, $\left.J_{1,2}=7.2, \mathrm{H}-7\right), 5.91\left(2 \mathrm{H}, \mathrm{s}, \mathrm{NH}_{2}\right), 6.64-6.66$ $\left(2 \mathrm{H}, \mathrm{d}, J_{1,2}=8.8,2 \mathrm{H}-2\right), 7.58-7.60\left(2 \mathrm{H}, \mathrm{d}, J_{1,2}=8.8,2 \mathrm{H}-3\right)$. 


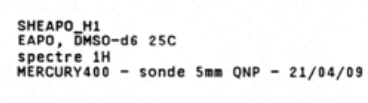

Pulse Sequence: s2pul

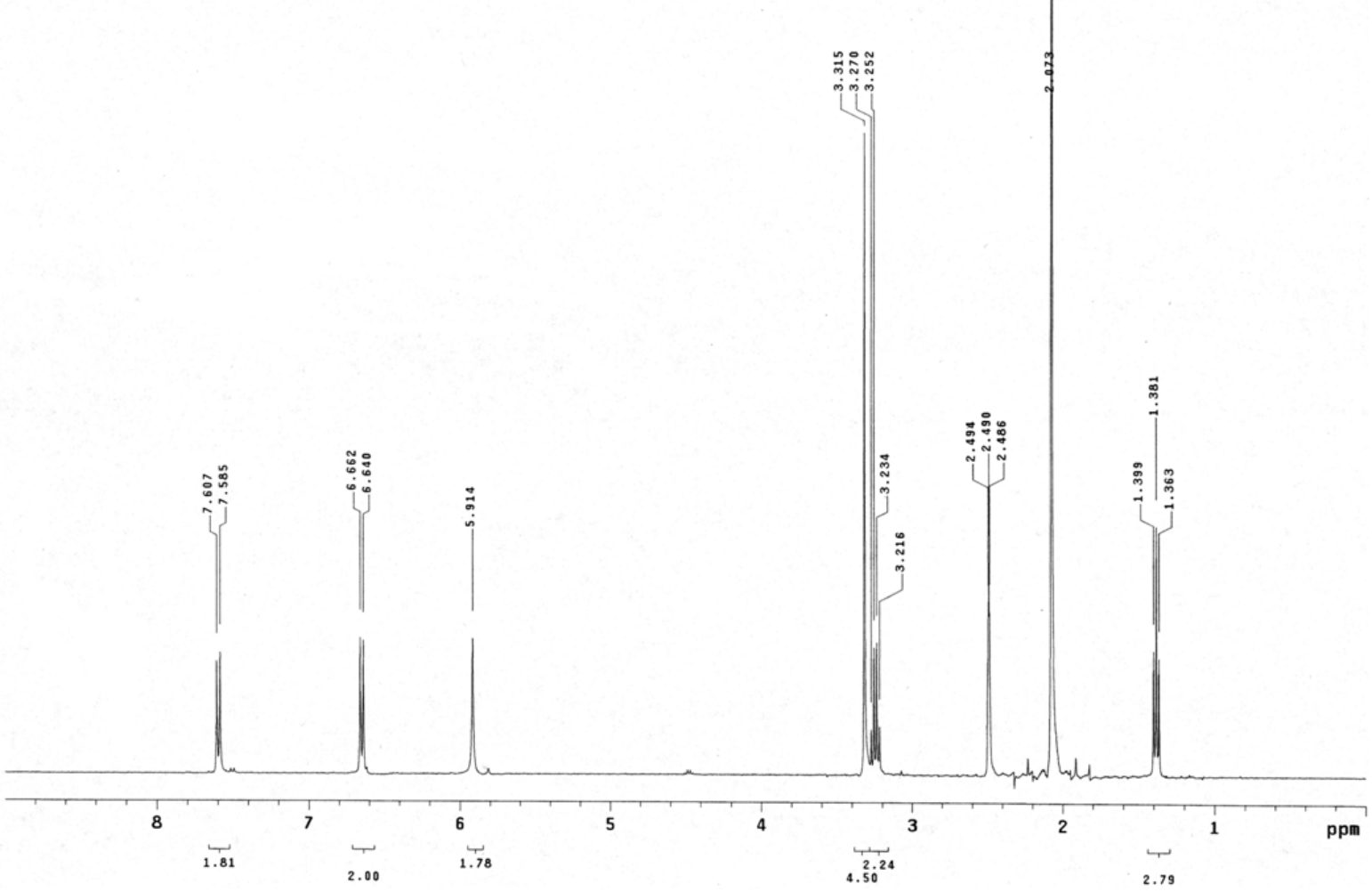

Fig 1. ${ }^{1} H$ NMR spectrum of compound III.

${ }^{13}$ C NMR (DMSO-d $)$ ) 14.90 (1C; C-8), 26.63 (1C; C-7), 109.38 (1C; C-4), 113.52 (2C; 2C-2), 127.86 (2C; 2C-3), 152.31 (1C; C-1), 161.40 (1C; C-6), 165.86 (1C; C-5).

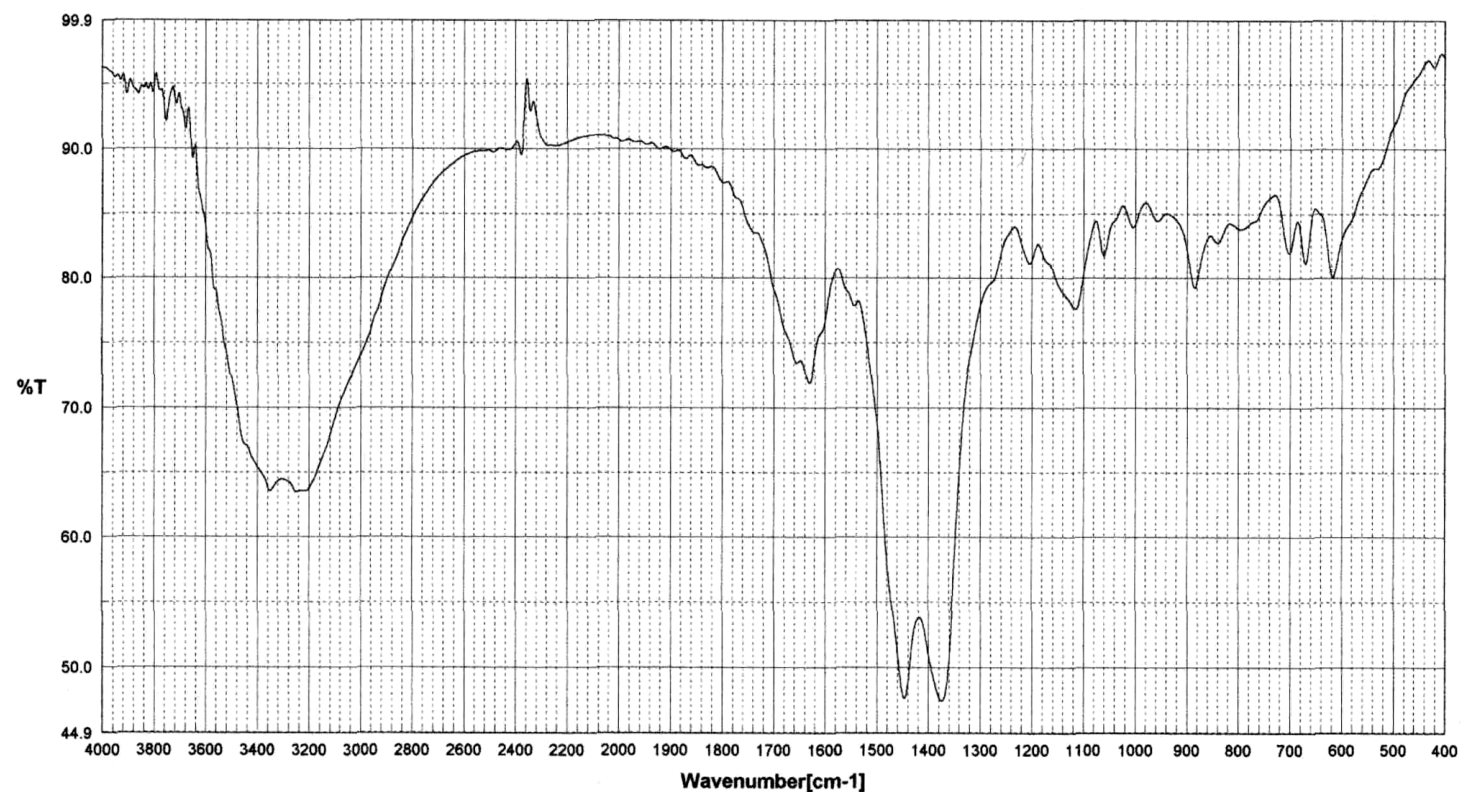

Fig 2. FTIR spectrum of compound III.

IR, $v_{\max } / \mathrm{cm}^{-1}: 2960(\mathrm{CH}$, aliphatic $), 1630.5 \quad(\mathrm{C}=\mathrm{N}$, oxadiazole), 1114.6 (C-O, oxadiazole). $\mathrm{mp} 98^{\circ} \mathrm{C}$.

Anal. Calcd. (\%) for $\mathrm{C}_{10} \mathrm{H}_{11} \mathrm{~N}_{3} \mathrm{OS}$ : C, 54.28; H, 5.01; N,
18.99; found: C, 54.3; H, 5.1; N, 19.1. MS (m/z): 222.07 $(\mathrm{M}+1)$. 


\section{Results and Discussions}

\subsection{Spectroscopic Details}

The synthetic route used for the preparation of compound (III) is shown in Scheme 1.

Compound (II) was obtained from commercially available 4-aminobenzoic hydrazide (I).

First, the oxadiazole ring formation reaction took place between the hydrazide group of compound (I), and carbon disulfide to give compound (II).

Compound (III) was also obtained from its precursor (II). Initially an alkylation reaction is introduced by using bromoethyl.

IR spectrum of (III) gave the expected $\mathrm{C}=\mathrm{N}$ band at 1630.5 $\mathrm{cm}^{-1}$, and $\mathrm{C}-\mathrm{H}$ band at $2960 \mathrm{~cm}^{-1}$. The stretch of oxadiazole

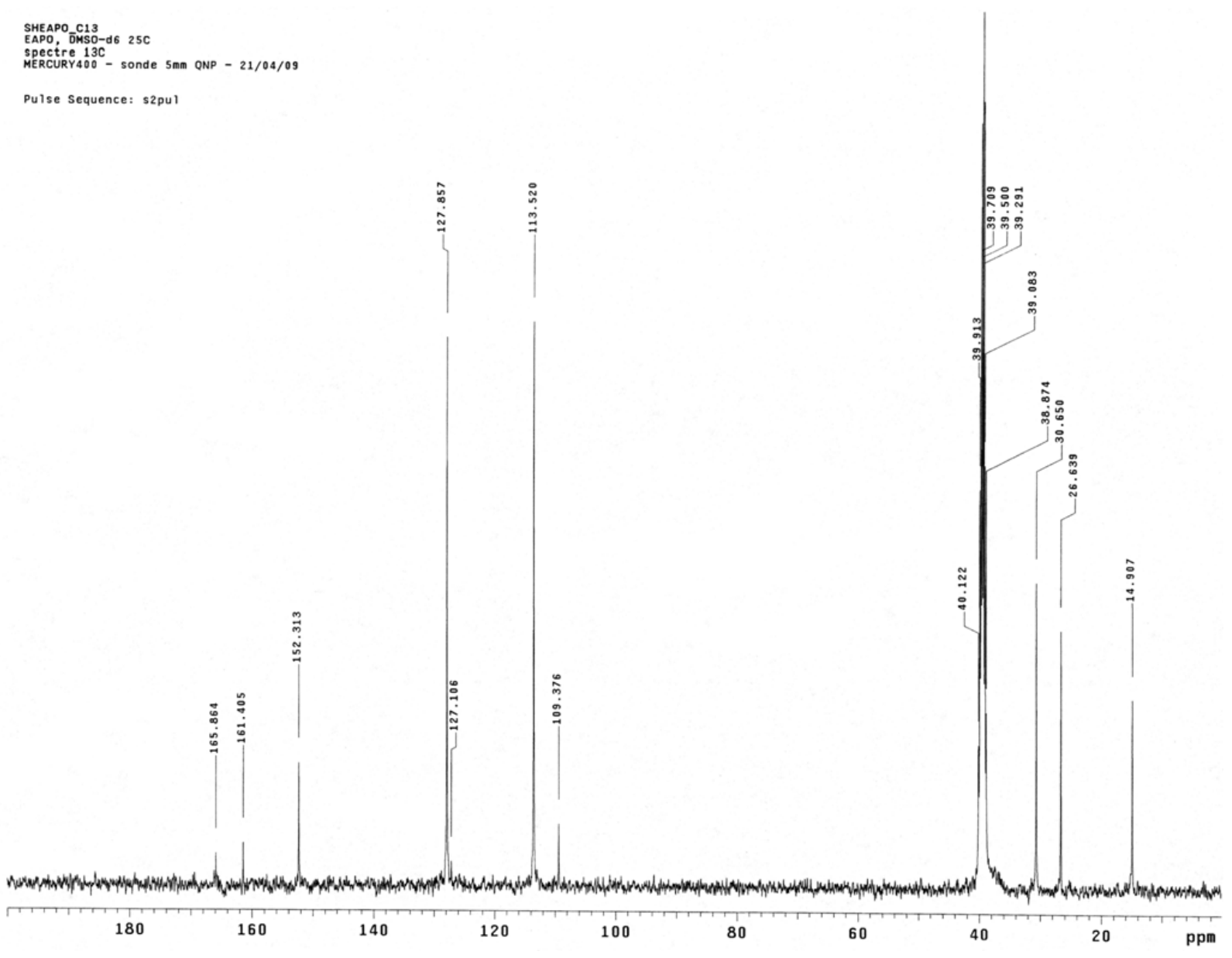

Fig 3. ${ }^{13}$ C NMR spectrum of compound III.

\subsection{XRD Pattern}

X-ray diffraction measurements were obtained using APD 2000 Diffractometer on powder diffraction system. The powder sample of (III) was gently ground in a mortar, loaded between two Mylar foils, and then fixed in the sample holder with a mask of suitable diameter $(7.0 \mathrm{~mm})$.

The XRD data were collected at $25^{\circ} \mathrm{C}$ using monochromic ring appeared clearly at $1114.6 \mathrm{~cm}^{-1}$ due to C-O. Mass spectrum of (III) showed molecular ion peak m/z (M+1) 222.

${ }^{1} \mathrm{H}$ NMR spectrum showed the expected five resonances for five different proton groups in their expected chemical shift regions.

Moreover, ${ }^{13} \mathrm{C}$ NMR spectrum showed also the expected peaks for all carbon environments in the molecule. It is worth to mention that the most characteristic peaks corresponding to $\mathrm{C}-\mathrm{SH}$, and $\mathrm{C}=\mathrm{N}$ appeared clearly at 161.4 , and $185.86 \mathrm{ppm}$ respectively.

Fig. 3 shows the ${ }^{13} \mathrm{C}$ NMR spectrum, and confirmed the expected structure of compound (III). It appeared new peaks for Ethyl group at 14.9, $26.6 \mathrm{ppm}$ comparing to compound (II). 


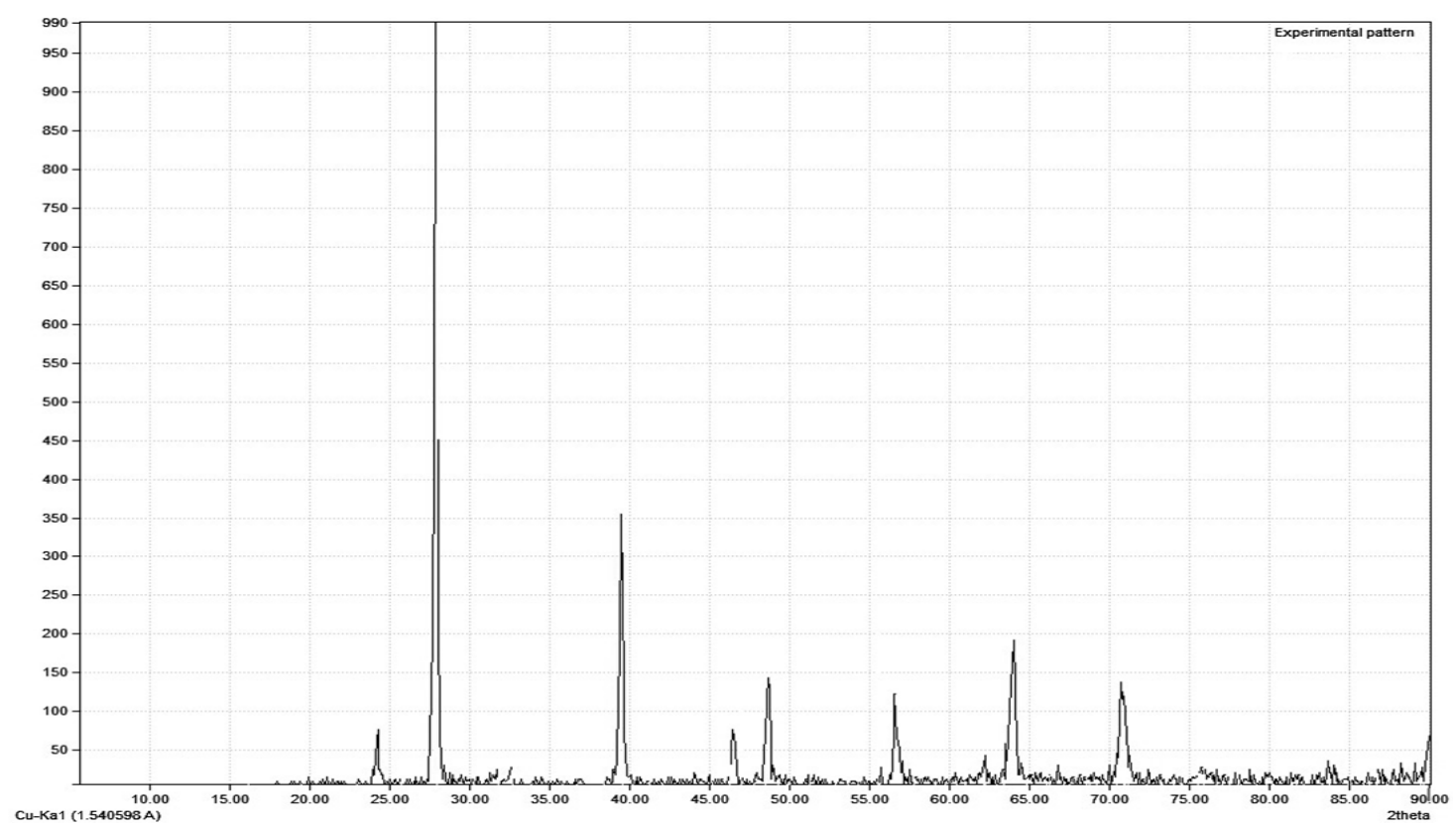

Fig 4. XRD pattern of compound (III).

The title compound, crystalizes in a type of cubic unit cell in the space group $P 2_{13}$. The molecule contains two rings; benzene and an 1,3,4-oxadiazole ring.

Thus, the secret behind this unique structure is its ability to form a cavity that holds the isomer to be separated over liquid crystals stationary phases. Moreover, this is one of the clues that gives our previously studied LCs stationary phases the high efficiency of separating isomer in GC [9].

Recently, many techniques have been employed to characterize and investigate structures of liquid crystalline phases. For example, polarized optical microscope is commonly used to identify the phase behaviors of liquid crystalline, in addition differential scanning calorimetry (DSC) is used to detect the thermal transitions associated with the different phases.

Table 1. Summary of crystal data of compound III

\begin{tabular}{ll}
\hline Molecule & Unit Cell \\
\hline $\mathrm{C}_{10} \mathrm{H}_{11} \mathrm{~N}_{3} \mathrm{OS}$ & Cubic, $P 2_{13}$ \\
$\mathrm{M}_{\mathrm{w}}=221.28$ & $a=b=c=9.1369 \AA$ \\
& $\alpha=\beta=\Gamma=90^{\circ}$ \\
& $\mathrm{V}=762.7 \AA^{3}$ \\
\hline
\end{tabular}

In all used techniques for liquid crystalline characterization, $\mathrm{X}$-ray scattering is by far the most useful one for probing the packing structures of liquid crystalline. In particular, X-ray scattering study of oriented powder samples enables us to obtain much important information on orientational and positional order of the molecular arrangements of liquid crystalline, which is essential for understanding their packing structures.

Hence, we may conclude that this study may give an overview on the separation mechanism of isomers, in liquid crystal stationary phases of gas chromatography. The title compound III, is synthesized and fully characterized by traditional spectroscopic techniques.

\section{Acknowledgements}

We greatly appreciate the assistance of all faculty and staff in the Department of Chemistry, Faculty of Sciences, and Higher Institute of Laser Research, especially to those who have kindly worked when solving the crystal structures.

\section{References}

[1] D. Demus, J. Goodby, G.W. Gray, H.-W. Spiess, in Handbook of Liquid Crystals, V. Vill, Ed.: VCH-Wiley: Weinheim, 1998.

[2] A. Seed, "Synthesis of self-organizing mesogenic materials containing a sulfur-based five-membered heterocyclic core," Chem. Soc. Rev., vol. 36, pp. 2046, 2007.

[3] A. Bishayee, R. Karmaker, A. Mandal, S.N. Kundu, M. Chatterjee, "Vanadium-mediated chemoprotection against chemical hepatocarcinogensis in rats; hematological and histological characteristics," Eur. J. Cancer Prev., vol. 6, pp. 58-70, 1997.

[4] C.R. Chitamber, J.P. Wereley, "Resistence to the antitumor agent Gallium nitrate in human Leukemic cells is associated with decreased gallium/iron uptake increased activity of iron regulatory protein-1, and decreased Ferritin production," J. Biol. Chem., vol. 272, pp. 12151-12157, 1997.

[5] A.K. Prajapati, V.P. Modi, "Bent-shaped mesogenic oxadiazole and thiadiazole derivatives from rod-shaped mesogenic hydrazide containing polar chloro group," Liq. Cryst., vol. 37, pp. 407-415, 2010.

[6] A.K. Prajapati, V.P. Modi, "Bent-shaped mesogenic oxadiazoles and thiadiazoles with terminal methyl group," Phase Transitions, vol. 83, pp. 634-649, 2010.

[7] A.K. Prajapati, V.P. Modi, "Mesogenic bent-shaped nitrooxadiazols and thiadiazoles," Liq. Cryst., vol. 38, pp. 191-199, 2011 
[8] M. Benalia et al. "Analytical study of three liquid crystals used as stationary phases in gas chromatography," Asian J Chem., vol. 19(3), pp. 1761-1771, 2007.

[9] E. Ghanem, S. Al-Hariri, "Preparation and thermodynamic behaviour of new nematic sulphur containing liquid crystal," Aust. J. Basic Appl. Sci., vol. 7(6), pp. 135-141, 2013.
[10] S. Sakagami, M. Nakamizo, "Application of liquid crystals for gas chromatography," Bull. Chem. Soc. Jpn., vol. 57, pp. 1157-1158, 1984.

[11] S. Abrahamsson, B. Dahlen, H. Lofgren, I. Pascher, S. Sundell, In Structure of Biological Membranes. Eds. Plenum Press: New York and London, 1977. 